\title{
REINTERPRETANDO O CONSTRUIR FRONDOSO: A CASA DE DUAS FRENTES E A VILA PAJUÇARA EM NATAL/RN - UMA PROPOSTA DE HIS SUSTENTÁVEL
}

\author{
RENTERPRETANDO EI CONSTRUIR FRONDOSO: LA CASA DE DOS FRENTES Y LA VILA \\ PAJUZARA EN NATAL/RN, UNA PROPUESTA DE HIS SOSTENIBLE
}

RENTERPRETING THE CONSTRUCTING FRONDOSO: THE HOUSE OF TWO FRONTS AND VLA PAJUÇARA IN NATAL/RN, A PROPOSAL OF SUSTAINABLE HS

\author{
VELOSO, MAÍSA FERNANDES DUTRA
}

Arquiteta, Doutora, Professora PPGAU/PPAPMA/DARQ/UFRN, e-mail: maisaveloso@gmail.com

\section{SILVA, HEITOR DE ANDRADE}

Arquiteto, Doutor, Professor PPGAU/PPAPMA/DARQ/UFRN, e-mail: heitor.andrade@ufrn.abea.arq.br

\section{MEDEIROS, LUCIANA DE}

Arquiteta, Doutora, Professora DARQ/UFRN, e-mail: medeiros.luciana@outlook.com

\section{MONTEIRO, VERNER MAX LIGER DE MELLO}

Arquiteto, Mestre, Professor DARQ/UFRN e IFRN, doutorando PPGAU/UFRN, e-mail: vernermonteiro@yahoo.com.br

\author{
DIONISI, ALESSIO PERTICARATI
}

Arquiteto, mestrando PPAPMA/UFRN, e-mail: alessiopdionisi@gmail.com

\section{ELALI, GLEICE AZAMBUJA}

Arquiteta, Psicóloga, Doutora, Professora PPGAU/PPAPMA/DARQ/UFRN, e-mail: gleiceae@gmail.com

\section{BATISTA, MARA RAQUEL DE ALMEIDA}

Graduanda em Arquitetura e Urbanismo DARQ/UFRN, e-mail: mararaquelab@gmail.com

\section{RESUMO}

Este artigo apresenta e discute o projeto, que obteve Menção Honrosa no Prêmio Armando de Holanda Cavalcanti (AHC) de Arquitetura, promovido pelo CAU/PE, voltado para arquitetos e urbanistas do país. A proposta de uma habitação de interesse social (HIS) sustentável consiste em uma solução à problemática atual vivenciada por moradores em condição de vulnerabilidade social da Zona Norte de Natal/RN, que estão sendo desapropriados e sofrem a ameaça de não permanecerem na área. $\mathrm{O}$ objetivo do projeto implica em conceber um conjunto habitacional para reassentar a população residente nos imóveis desapropriados da Avenida Moema Tinoco. Também, pretende aplicar princípios de AHC, considerando necessidades, conceitos e tecnologias contemporâneas. O processo projetual adotado incluiu ações analíticas, conceptivas e avaliativas, em um percurso cíclico e dialógico de naturezas complexa e colaborativa. Entre os resultados, ressaltamse os princípios que buscaram articular demandas concretas do lugar, parâmetros bioclimáticos pertinentes e valores simbólicos da região. Foram propostas 43 unidades unifamiliares, sendo uma acessível, com bom desempenho bioclimático (construir frondoso), baixo custo e possibilidades de ampliação. A ideia da casa com duas frentes responde aos condicionantes do projeto, em que as unidades foram distribuídas com acessos pelo Noroeste ou Sudeste, porém com os quartos sempre voltados para o Sudeste (ventos dominantes). Concluímos que o exercício de concepção e desenvolvimento de um projeto colaborativo converteu-se em uma experiência pertinente para a prática reflexiva e promoção da qualidade arquitetônica. Contribui para o debate sobre alternativas mais humanas e justas ao problema das desapropriações na região de intervenção.

PALAVRAS-CHAVE: HIS; Arquitetura Sustentável; BIM. 


\section{RESUMEN}

Este artículo presenta y discute el proyecto, que obtuvo Mención Honrosa en el Premio Armando de Holanda Cavalcanti (AHC) de Arquitectura, promovido por el CAU / PE, orientado a arquitectos y urbanistas del país. La propuesta de una vivienda de interés social sostenible consiste em una solución a la problemática actual vivida por habitantes en condición de vulnerabilidad social de la Zona Norte de Natal / RN, que están siendo expropiados y sufren la amenaza de no permanecer en el área. El objetivo del proyecto implica concebir un conjunto habitacional para reassentar la población residente en los edificios expropiados de la Avenida Moema Tinoco. También, pretende aplicar principios de AHC, considerando necesidades, conceptos y tecnologías contemporáneas. El proceso proyectual adoptado incluyó acciones analíticas, conceptivas y evaluativas, en un recorrido cíclico y dialógico de naturaleza compleja y colaborativa. Entre los resultados, se resaltan los principios que buscaron articular demandas concretas del lugar, parámetros bioclimáticos pertinentes y valores simbólicos de la región. Se proponían 43 unidades unifamiliares, siendo una accesible, con buen desempeño bioclimático (construir frondoso), bajo costo y posibilidades de ampliación. La idea de la casa com dos frentes responde a los condicionantes del proyecto, en que las unidades fueron distribuidas con accesos por el Noroeste o Sudeste, pero com las habitaciones siempre orientadas hacia el Sudeste (vientos dominantes). Concluimos que el ejercicio de concepción y desarrollo de um proyecto colaborativo se ha convertido en una experiencia pertinente para la práctica reflexiva y promoción de la calidad arquitectónica. Contribuye al debate sobre alternativas más humanas y justas al problema de las expropiaciones en la región de intervención.

PALABRAS CLAVE: HIS; Arquitectura sostenible; BIM.

\section{ABSTRACT}

This paper presents and discusses the project that received an Honorable Mention at the Armando de Holanda Cavalcanti Architecture Award (AHC), event promoted by the CAU/PE aimed to architects and urbanists of Brazil. The proposal of a sustainable Social Interest Housing (SIH) is presented as a solution for the current situation of social vulnerability lived by the residents of Zona Norte in Natal, RN, who are being expropriated and threatened of not being able to stay in the area. Thus, the project aims to conceive a housing complex to resettle the residents from the expropriated houses in the Moema Tinoco Street. Also, it is intended to apply the AHC principles, taking into consideration contemporary needs, concepts and technologies. The design process adopted included analytical, conceptive and evaluative actions developed in a cyclical and dialogical course of complex and collaborative nature. The results obtained highlighted the principles that aimed to incorporate the specific demands of the place, relevant bioclimatic parameters and symbolic values of the region. Therefore, a total of 43 single-family units were proposed, among those one with accessible features, presenting good bioclimatic performance ("building leafy"), low cost and the possibility of future expansion. The idea of a house with two entrances meet the project requirements, in which the units were distributed with accesses by the Northwest or Southeast, but with the rooms always facing the Southeast (prevailing winds). In conclusion, the exercise of the conception and development of a collaborative project showed as an important experience for a reflexive practice and to promote architectural quality. Furthermore, it contributes to the debate on fairer and more human alternatives for the expropriation problem in the area of intervention.

KEYWORDS: Social housing. Sustainable Architecture. BIM.

\section{INTRODUÇÃO}

Este artigo apresenta e discute um projeto arquitetônico desenvolvido de acordo com os requisitos estabelecidos no edital do concurso No 01/2018 - Prêmio Armando de Holanda Cavalcanti (AHC) de Arquitetura, promovido pelo CAU/PE (Conselho de Arquitetura e Urbanismo de Pernambuco) na modalidade profissional, voltado para arquitetos e urbanistas de todo país, mas tendo como área de intervenção os estados do Nordeste brasileiro.

O projeto, concebido pela equipe vinculada ao Laboratório de Projetos Integrados (LAPIs) e ao Grupo PROJETAR do Curso de Arquitetura e do Programa de Pós-graduação Profissional em Arquitetura, Projeto e Meio Ambiente da UFRN/Natal ${ }^{1}$, obteve Menção Honrosa no referido concurso. O Prêmio Armando de Holanda Cavalcanti 2018 teve como objetivo:

(...) estimular e promover a elaboração de propostas no campo da Habitação de Interesse Social (HIS), tendo por base a reflexão, difusão, atualização e aplicação das ideias propostas pelo arquiteto Armando de Holanda Cavalcanti, em especial, na sua obra "Roteiro para Construir no Nordeste", de forma a estimular a criação de uma HIS Sustentável, bem como a interface dessa arquitetura com as novas metodologias e ferramentas tecnológicas projetuais como o BIM (Building Information Modeling, ou Modelagem da Informação da Construção), entre os profissionais e estudantes de arquitetura e urbanismo (CAU-PE, 2018, grifos nossos).

A proposta de uma Habitação de Interesse Social (HIS) sustentável foi alicerçada em uma problemática atual vivenciada por moradores e usuários de dois bairros da Zona Norte de Natal, Rio Grande do Norte: a duplicação da Avenida Moema Tinoco no âmbito do Programa Pró-Transportes, que visa facilitar o acesso ao aeroporto internacional e às praias do litoral norte do Estado, implica na desapropriação de imóveis e no reassentamento de famílias residentes, comerciantes e prestadores de serviço, predominantemente, em condição de vulnerabilidade social. O eixo de intervenção abrange os bairros Lagoa Azul e Pajuçara e inclui a ZPA-9 (Zona de Proteção Ambiental), a Área Especial de Interesse Social (AEIS) do Gramorezinho e uma Zona de Segurança de Alimentar (PMN/SEMURB, 2012). Em razão dos baixos valores estabelecidos pelas instituições do Governo do Estado envolvidas no projeto para pagamento aos ocupantes dos imóveis desapropriados, as pessoas afetadas pelo processo estão ameaçadas de não conseguirem permanecer nas proximidades, apesar de existirem casos de ocupações que ultrapassam vinte anos.

O projeto pautou-se nos seguintes objetivos:

i) Elaborar, em nível de estudo preliminar, um projeto arquitetônico de um conjunto habitacional de interesse social destinado prioritariamente ao reassentamento de parte da população residente ou usuária dos imóveis desapropriados na Avenida Moema Tinoco, na zona Norte de Natal; 
ii) Aplicar na proposta os princípios constantes no livro Roteiro para Construir do Nordeste, de Armando de Holanda Cavalcanti, adequando-os às necessidades, conceitos e tecnologias contemporâneas, como os de Arquitetura Sustentável e o BIM (Building Information Modeling ou Modelagem de Informação da Construção);

iii) Utilizar elementos da cultura arquitetônica do lugar, tanto em termos tipológicos como construtivos;

iv) Valorizar a diversidade de usos e de formas de apropriação e a integração entre os espaços privados e coletivos/públicos que integram o conjunto e seu entorno.

Além dessa introdução e das conclusões, o artigo foi estruturado em cinco sessões denominadas: "O terreno de intervenção"; "O processo projetual"; "Vila Pajuçara: a implantação do conjunto edilício"; "A unidade habitacional: a casa de duas frentes"; e "As tecnologias construtivas empregadas".

\section{DESENVOLVIMENTO}

\subsection{O TERRENO DE INTERVENÇÃO}

O terreno escolhido (Figura 1) para o exercício de intervenção projetual é de domínio público, e situa-se próximo à Avenida Moema Tinoco, no bairro Pajuçara, uma área de Operação Urbana de Adensamento Básico do Município de Natal/RN, com ênfase na habitação social, conforme expresso no Plano Diretor da cidade (PMN, 2007). É dividido em dois setores por uma via central que o corta longitudinalmente e alguns caminhos naturais de pedestres e carros no sentido transversal. O solo é arenoso, recoberto por gramíneas e algumas árvores de médio porte. Há uma declividade natural de aproximadamente 8 metros no sentido da Moema Tinoco. Nele também já existem um campo de futebol e uma quadra de vôlei. $O$ entorno é constituído, essencialmente, por residências unifamiliares térreas, pequenos comércios de bairro e duas instituições: uma igreja e uma escola, próxima ao campinho.

A área total de intervenção é de $19.466 \mathrm{~m}^{2}$. Para essa área urbana, o Plano Diretor da cidade (PMN, 2007) define uma taxa de ocupação máxima de $80 \%$, garantindo o mínimo de $20 \%$ de solo permeável. Os recuos mínimos permitidos pelo Código de Obras (PMN, 2004) são de 3,00m (frontal) e 1,5 m (lateral).

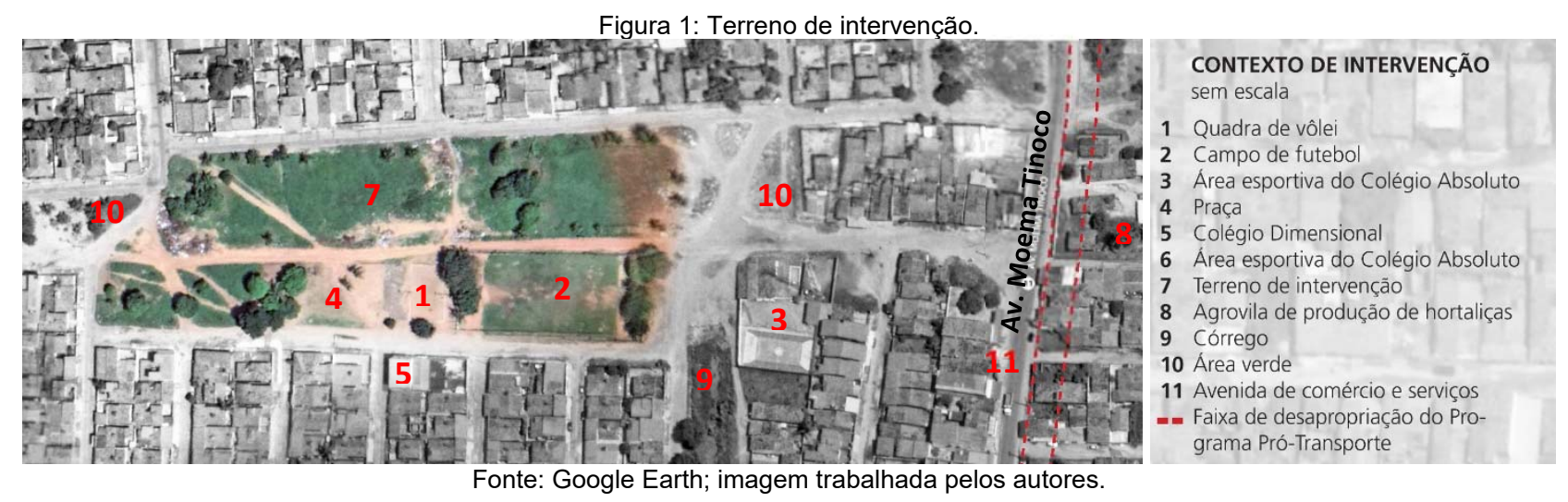

\subsection{O PROCESSO PROJETUAL}

O processo projetual adotado nesta experiência tem a sua gênese no próprio conceito central adotado uma reinterpretação do princípio "Construir Frondoso", de Armando de Holanda Cavalcanti, em seu Roteiro para Construir no Nordeste (HOLANDA, 1976). Conforme Boudon et al (2000), o projeto não se reduz a uma atividade de composição gráfica. Está na intersecção de processos intelectuais e de atividades práticas (técnico-operativas) de concepção dentro de um contexto complexo de fatores sociais e econômicos que Ihes condicionam. Boutinet (2000) acrescenta que o projeto significa "pré-visão"; projeção, antecipação de ações a serem realizadas em um futuro próximo. Busca o controle, a resolução de problemas, bem como a tomada de decisões em favor de soluções espaciais. Consiste em um meio pelo qual o projetista concretiza, materializa e, ao mesmo tempo, expressa ideias e intenções. Representa, nesse sentido, a sistematização de dados e de ideias. Para esse autor, o projeto é da ordem do processo na medida em que a diretriz avança e deixa-se alterar. 
Lawson (2011) sintetiza que o processo projetual contempla três fases básicas: a análise (dedicada à identificação dos principais elementos que compõem o problema de projeto), a síntese (associada à fase criativa dos estágios de decisão), e a avaliação (compromissada com a garantia de que a solução proposta seja a mais aceitável). As soluções arquitetônicas consistem, portanto, em um esforço crítico de análise e síntese de definição de um problema e de suas potenciais soluções para intervenção no espaço. Essas soluções se tratam de hipóteses, que normalmente são consequências de análises, mas se distinguem dessas por consistirem em escolhas. Quando alvos de avaliações (por meio de simulações, por exemplo), são desenvolvidas e aperfeiçoadas, configurando um esforço permanente de reduções de incertezas. Assim sendo, o processo projetual adotado incluiu ações de natureza analítica, conceptiva (síntese) e avaliativa (desenvolvimento e simulação do desempenho da habitação proposta). Essas práticas não foram lineares, mas cíclicas e dialógicas, configurando-se um percurso de complexidade progressiva, sempre feito de maneira conjunta e colaborativa, com base na experiência e especialidade de cada membro da equipe.

Em uma primeira etapa, procedeu-se à escolha e apropriação de um problema de projeto, a partir de demandas sociais existentes, da experiência dos projetistas sobre a realidade da cidade onde atuam (Natal/RN), de consultas em fontes secundárias (trabalhos acadêmicos e periódicos locais) e primárias (potenciais usuários das habitações, visitas in loco à área de conflito - trecho das obras da avenida Moema Tinoco, e a definição de um terreno para reassentamento de parte da população atingida, em especial as mais vulneráveis, em área de interesse social). A equipe também analisou as restrições e requisitos de projeto, definidos nos termos do edital desse concurso mencionado, sobretudo no que se refere aos princípios para construções adequadas ao clima da região, difundidos por Holanda (1976).

Em uma segunda etapa, propositiva, foram realizadas pesquisas sobre materiais e técnicas construtivas adequadas ao projeto, bem como projetos correlatos de HIS sustentáveis contemporâneas. Com base nessas reflexões, surgiram as primeiras hipóteses projetuais expressas em variados meios, principalmente gráficos, com auxílio de ferramentas de rápida definição, como croquis a mão livre e software como o Sketchup. Focou-se, inicialmente, no módulo da unidade habitacional expansível, concomitantemente às possibilidades de implantação na área de intervenção, seguindo os princípios de sustentabilidade e os conceitos adotados. Em uma terceira etapa, de desenvolvimento do projeto, a plataforma BIM $^{2}(R e v i t)$ foi sendo incorporada ao processo, bem como outros recursos de simulação e avaliação de desempenho ambiental do edifício e de seu conjunto (como o CFD e o Flow Design). Por fim, foram utilizados recursos de representação e editoração gráfica como PhotoShop e InDesign associados à expressão textual/diagramática, para apresentar os conceitos e soluções propostos em três pranchas tamanho A2, conforme as normas do concurso.

\subsection{VILA PAJUÇARA: A IMPLANTAÇÃO DO CONJUNTO EDILÍCIO}

Os princípios que nortearam a concepção da unidade habitacional e a implantação do conjunto buscaram estabelecer um diálogo entre as demandas concretas do lugar, os princípios bioclimáticos defendidos por Armando de Holanda, e os valores simbólicos da região. A vila "Pajuçara", também, nome do bairro, que significa "guerreiro forte e robusto", representa simbolicamente a população na sua luta pela permanência no local, dando-Ihes alternativas de moradia, sociabilidade e sustento econômico. O tipo "vila de casas térreas alpendradas e geminadas duas a duas" visou preservar a cultura local, em que se observam redes de relações sociais e a coexistência de moradias com comércios e serviços de bairro, além de práticas de agricultura urbana em hortas e pomares domésticos, muito comuns nessa região da periferia de Natal. Foram propostas 43 unidades unifamiliares, sendo uma acessível, com bom desempenho bioclimático (construir frondoso), baixo custo (construir com pouco) e possibilidades de ampliação (com possibilidade de conversão em uso misto). Buscou-se criar três níveis de domínio: público (áreas de acesso irrestrito das pracinhas e horta comunitária), coletivo (quintais de acesso restrito aos moradores de quadras, separados por cercas verdes) e privado (as unidades habitacionais) - (Figura 2). 


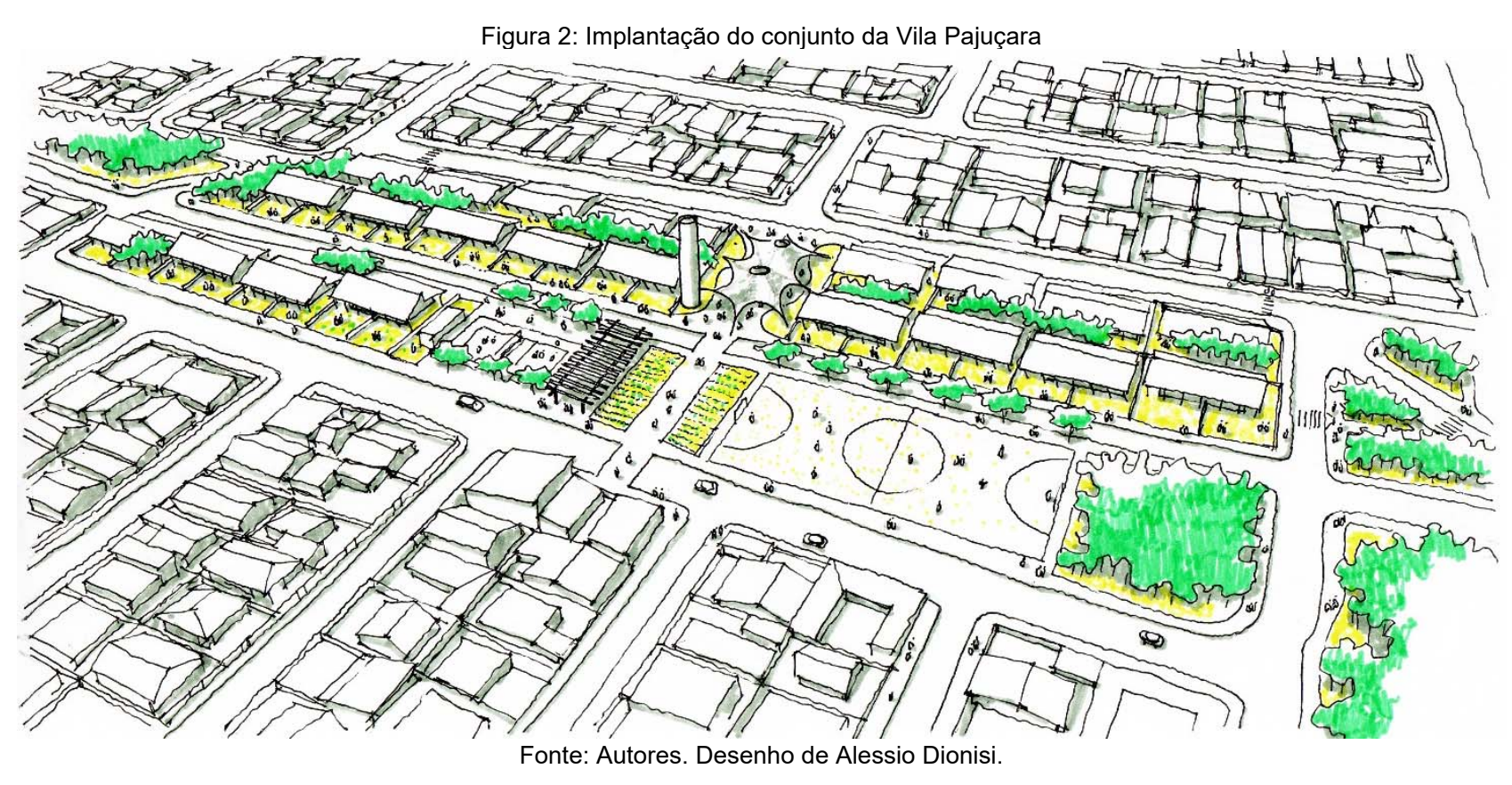

As áreas livres públicas preservam, no sentido longitudinal, os equipamentos de lazer e esporte existentes (quadras de futebol e vôlei) e acrescentam, no sentido transversal, espaços para hortas orgânicas, atividades de convívio e comércio, como é o caso da praça central sob estrutura tensionada, dedicada a feirinhas de hortaliças e outras atividades coletivas da comunidade. Esse eixo, também tem a função simbólica de conectar a escola com o sistema viário existente, onde já existem fluxos naturais de pedestres. É nele que também é proposta a caixa d'água coletiva do conjunto, elemento vertical que marca a presença da vila "dos heróis da resistência" na paisagem horizontal do bairro.

As unidades, conjugadas duas a duas, foram dispostas com distintos recuos frontais de 3 ou 6 metros, a fim de otimizar as instalações hidro sanitárias e possibilitar um bom aproveitamento da área, favorecendo a permeabilidade tanto de fluxo de pessoas como dos ventos dominantes (Sudeste). Merece destaque a configuração dos lotes - voltados para as duas principais vias públicas que delimitam as áreas de implantação, pelo Noroeste e pelo Sudeste -, que definiu a denominação "casas com duas frentes", que podem ser acessadas por ambos os lados, mas mantendo os ambientes de longa permanência favoráveis à ventilação dominante.

\subsection{A UNIDADE HABITACIONAL: A CASA DE DUAS FRENTES}

O conceito central do projeto, Construir Frondoso de Armando de Holanda (Figura 3), está articulado a princípios da arquitetura bioclimática e sustentável, relacionando-se à problemática local (atendimento às demandas da população alvo de desapropriações e preservação a vida comunitária) e aos princípios de HIS, contemplando racionalidade construtiva e uso de tecnologias e linguagens contemporâneas.

Figura 3: Construir frondoso

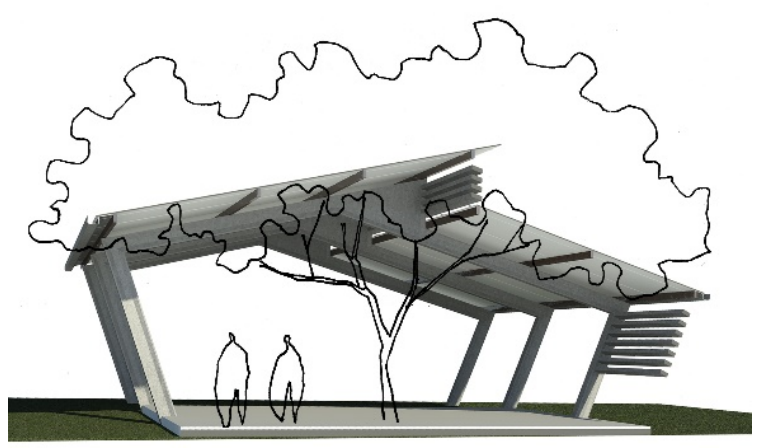

Fonte: Autores.

Croquis a mão livre de Alessio Dionisi, inspirado na árvore de Armando de Holanda (1976), inserido sobre Perspectiva de Verner Monteiro elaborada no Revit. 
A ideia da casa com duas frentes responde aos condicionantes de projeto. Uma frente volta-se para a rua e a outra para o quintal/interior do lote, ambos espaços de convivência social ou familiar. As unidades foram distribuídas com acessos pelo Noroeste ou Sudeste, com os quartos sempre posicionados para o Sudeste (ventos dominantes). Desse modo, buscou-se um leiaute para a sala de estar e cozinha (integradas) que pudesse ser espelhado, possibilitando acesso pelos dois lados, tendo o alpendre como elemento de transição entre exterior e interior. O eixo de circulação de acesso ao quarto e ao banheiro foi centralizado e as instalações hidro sanitárias concentradas, deixando livres as paredes para a expansão lateral. (Figura 4).

Figura 4: Plantas-tipo e expansões das unidades habitacionais
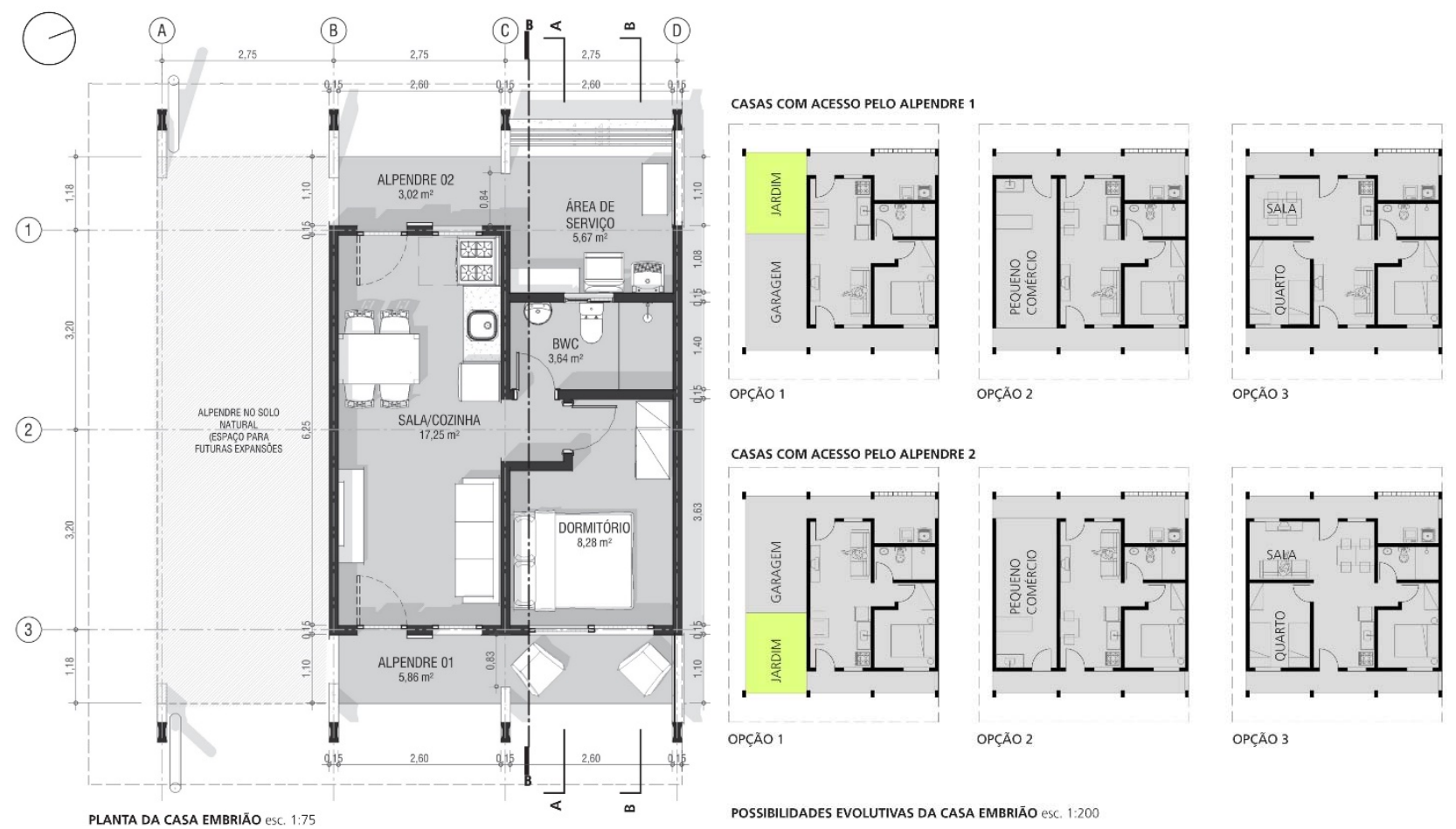

OPÇÃO 1

OPÇÃO 2

OPÇÃO 3

CASAS COM ACESSO PELO ALPENDRE 2

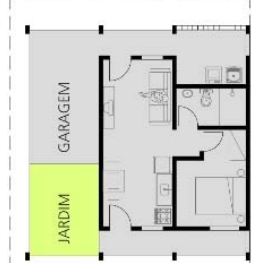

OPÇÃO 1

POSSIBIIIDADES EVOLUTIVAS DA CASA EMBRIĀO ESC 1.200

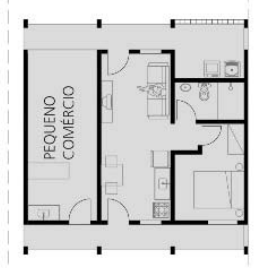

$\mathrm{OPÇĀO} 2$

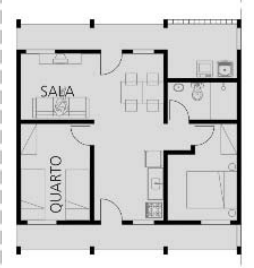

OPÇÃO 3

Fonte: Autores.

A casa térrea alpendrada é um tipo habitacional comum na região, principalmente na zona de proteção alimentar e adjacências, que além de reduzir os custos da unidade, evita barreiras arquitetônicas e favorece a expansibilidade. A área do "embrião + alpendre" é de $48 \mathrm{~m}^{2}$ e a de "expansão completa + alpendre", $71 \mathrm{~m}^{2}$. Ou seja, todas as unidades receberão $71 \mathrm{~m}^{2}$ de área coberta, contudo, apenas $48 \mathrm{~m}^{2}$ serão entregues com o acabamento completo. Isso possibilitou o uso do CUB de R\$ $825,00 / \mathrm{m}^{2}$ para HIS térreas (SINDUSCON/RN, 2018). Logo, a estimativa de custo do projeto embrião, segundo esse parâmetro, é de RS 39.600,00, podendo se estender até $\mathrm{R} \$ 58.577,00$ (ampliação máxima). A planta-baixa da unidade padrão tem vãos modulados com $2.60 \mathrm{~m}$ de largura. (Figuras 5,6 e 7 ). O programa é composto por sala de estar, cozinha, quarto, banheiro, área serviço e alpendres. A expansão permite incluir mais um quarto, comércio ou garagem, entre outros cômodos, ou a conjugação de várias opções. A solução permite, assim, considerável diversidade de formas de apropriação.

Figura 5: Corte B

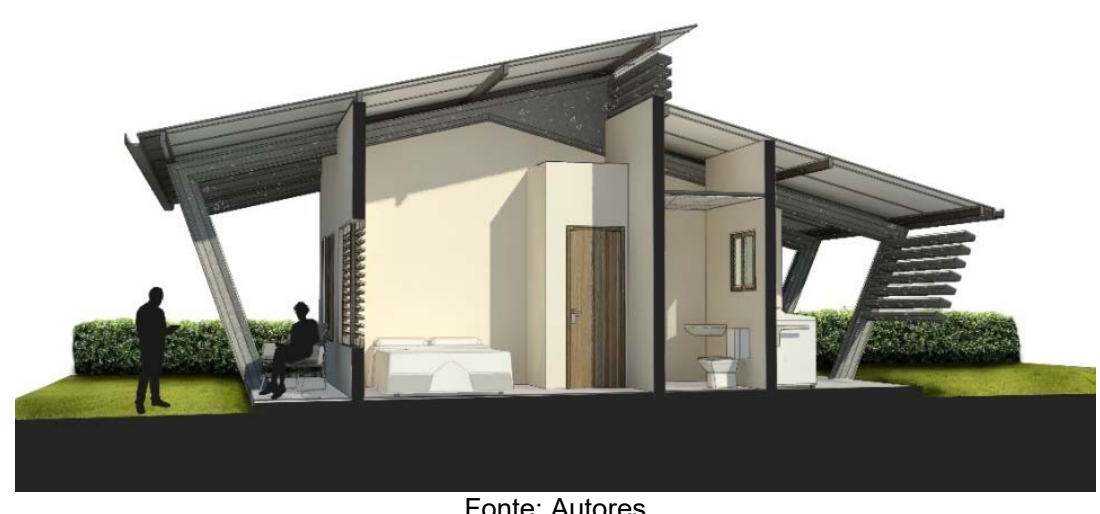

Fonte: Autores 
Figura 6: Vista do alpendre 1

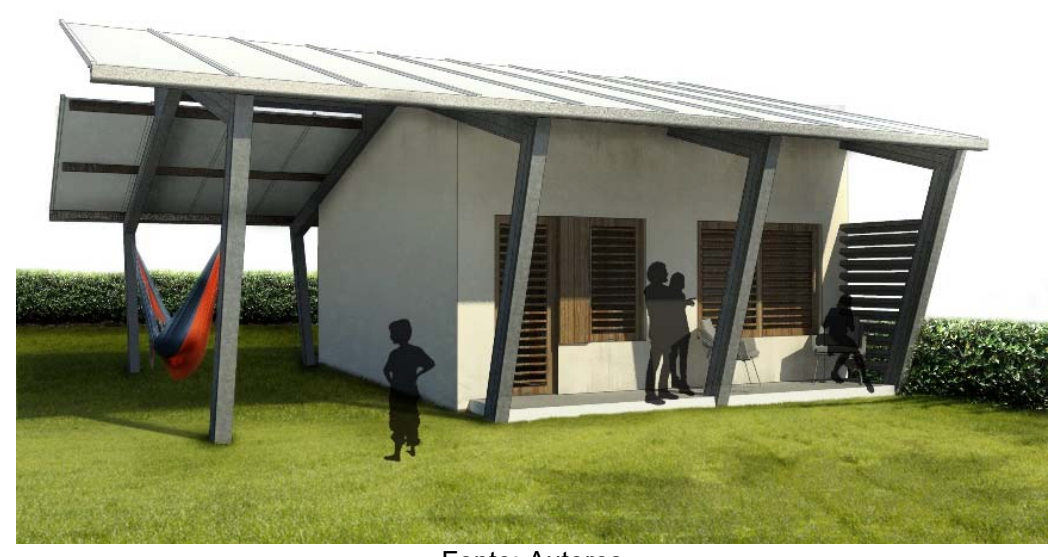

Fonte: Autores

Figura 7: Vista do alpendre 2

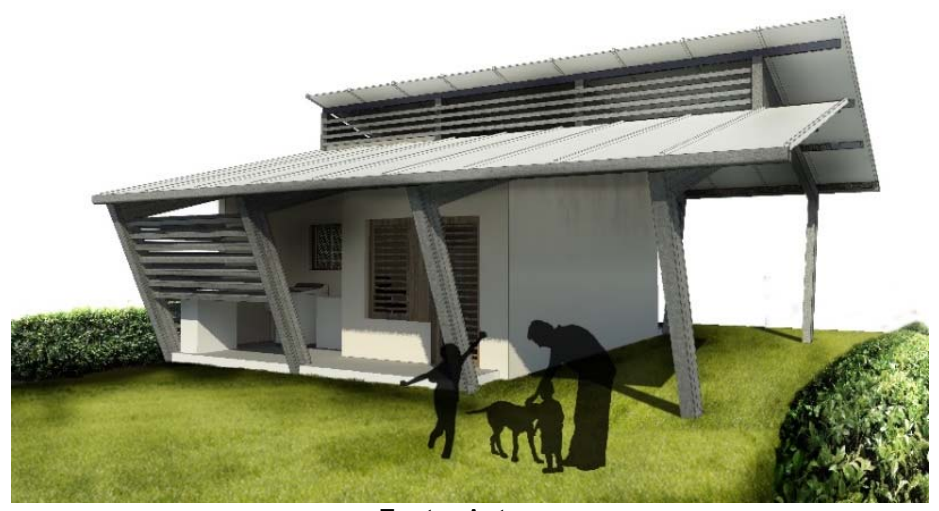

Fonte: Autores

Quanto ao conforto e à sustentabilidade ambiental, as principais estratégias utilizadas foram: ambientes de longa permanência para o Sudeste e com ventilação cruzada; janelas e portas grandes, vazadas e sombreadas; coberturas ventiladas com telhas termo-acústicas e pé-direito alto $(3,00 \mathrm{~m}$ nos pontos mais baixos e inclinação 25\%); paredes sombreadas por alpendres e beirais; isolamento acústico lateral (bloco de concreto), paredes vazadas (brises); ausência de muros (cercas verdes dividem os lotes); soluções de baixo impacto ambiental; captação de águas pluviais (reservadas em cisternas individuais) e reuso de águas servidas (Figuras 8 e 9).

Essas estratégias projetuais são consonantes com os princípios de Holanda (1976), notadamente: criar sombras, recuar paredes, vazar muros, proteger as janelas, continuar os espaços.

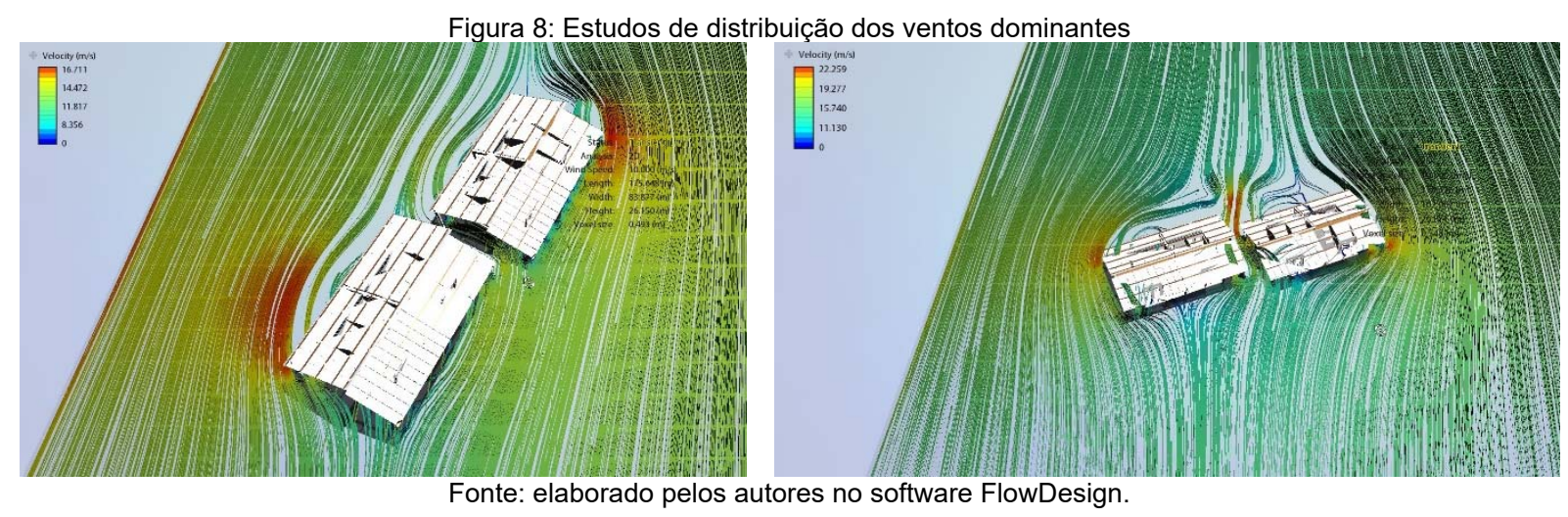


Figura 9: Estudos de incidência solar direta

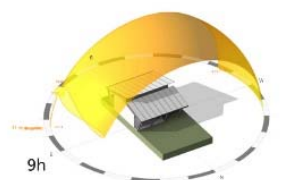

OLSTICIO DE VERĀO

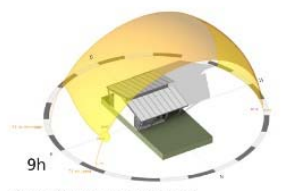

SOLSTICIO DE INVERNO

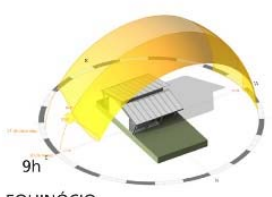

EQUINÓCIO

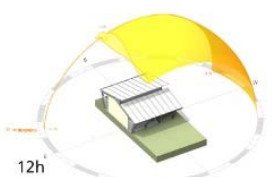

$15 \mathrm{~h}$
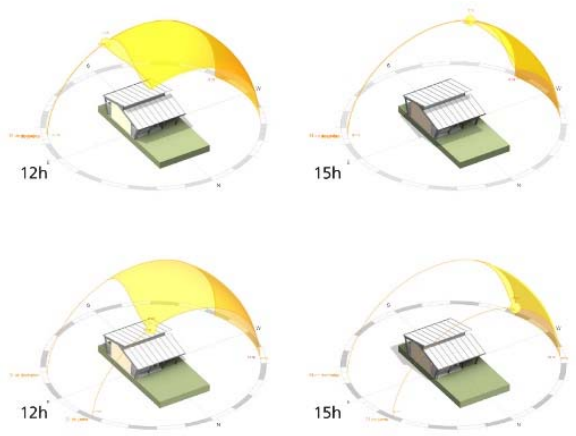

$12 \mathrm{~h}^{\mathrm{T}}$

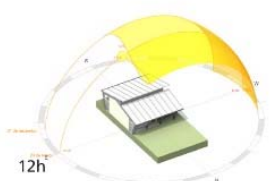

$15 \mathrm{~h}$

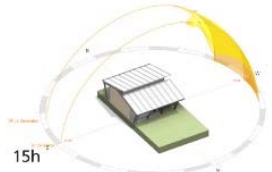

Fonte: elaborado pelos autores no software Revit.

Além disso, o estímulo à agricultura familiar (hortas e pomares orgânicos) e a horta-escola favorecem a sustentabilidade econômica e a integração social entre os moradores do conjunto e do bairro, além de se alinharem com o princípio de "conviver com a natureza" (Holanda, 1976).

\subsection{AS TECNOLOGIAS CONSTRUTIVAS EMPREGADAS}

O projeto buscou a racionalidade construtiva, soluções de baixo impacto ambiental, custo reduzido e adaptáveis aos programas de financiamento de HIS (PMCMV-entidades e outros), com CUB $/ \mathrm{m}^{2}$ abaixo de $\mathrm{R} \$ 1.000,00$. Foram utilizados técnicas e materiais que produzem pouco resíduo, como: i) pórticos e blocos de concreto pré-moldados (respectivamente para a estrutura de apoio e vedações) produzidos na própria Região Metropolitana de Natal, de rápida execução e que facilitam a modulação (ambientes múltiplos de $0,20 \mathrm{~m}$ ); ii) pisos em cimento queimado para as áreas internas, muito comuns na região; iii) aproveitamento de materiais de demolição (tijolos para contra-piso e nos pisos das áreas externas, e madeiras e telhas para as cercas/divisórias entre lotes), tendo em conta a economia, as tradições locais e o reaproveitamento sustentável; iv) coberturas em telhas metálicas termo-acústicas, com excelente desempenho e fácil acesso (fabricadas em Vitória de Santo Antão/PE), fixadas em terças de madeiras da região (angico, aroeira ou brejuí); iv) esquadrias em madeiras da região, com venezianas móveis (tipo 'tabicão', denominação local) (Figura 10).

Figura 10: Compontes construtivos

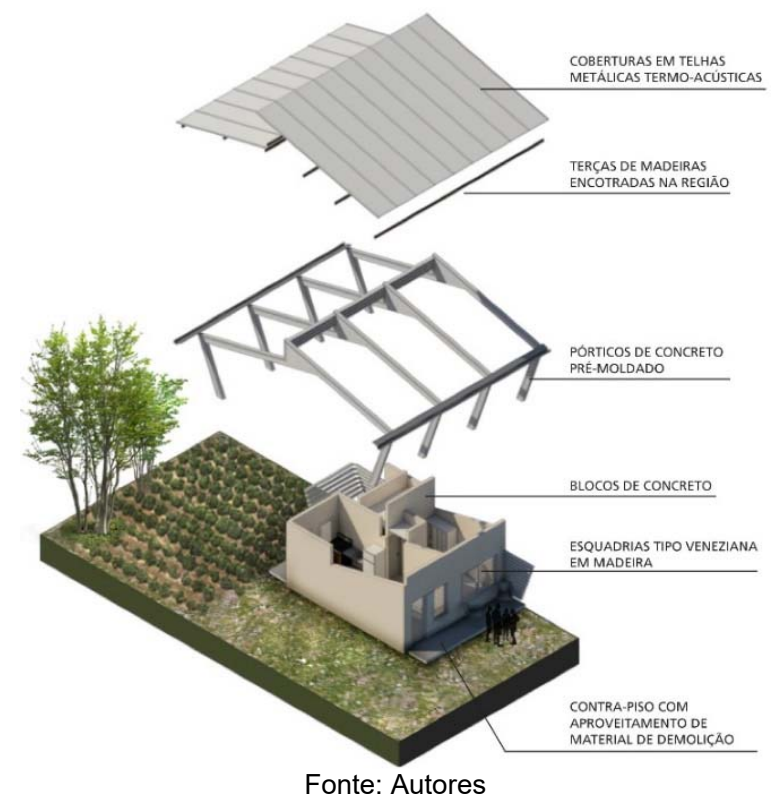


O uso desses elementos e das soluções projetuais empregadas, sua modelagem na plataforma BIM e simulação de desempenho nos software CFD e FlowDesign atestam a pertinência e a aplicabilidade dos preceitos de Armando de Holanda Cavalcanti na habitação social contemporânea, garantindo às casas de duas frentes da Vila Pajuçara a robustez, a praticidade e o conforto de que são dignos os "guerreiros" que irão habitá-las, símbolos da resistência e da luta pela permanência no local.

\section{CONSIDERAÇÕES FINAIS}

Em síntese, pode-se destacar que os conceitos e princípios considerados no projeto foram estruturados em dois grupos. O primeiro de natureza mais conceitual remete a três aspectos: i) a vida comunitária, em que se destacam os hábitos de cultivo doméstico de hortaliças, o convívio coletivo e o caráter de habitações de interesse social; ii) a noção de vilas, vinculando-se a ideia de casa de campo, vida em comunidade e autossuficiência parcial; iii) a etimologia da palavra "Pajuçara", nome do bairro onde está situado o terreno de intervenção projetual e significa "guerreiro robusto".

O segundo grupo, de natureza mais técnica, refere-se a dois parâmetros. Um diz respeito à Arquitetura Bioclimática. Leva em consideração a adequação do projeto ao lugar, tendo em conta o clima, a topografia, o tipo de solo, a vegetação, bem como conforto térmico, lumínico e acústico, mas, sobretudo, considera os princípios defendidos por Armando de Holanda (1976): criar sombras, recuar paredes, vazar muros, proteger as janelas, abrir as portas, continuar os espaços, construir com pouco, conviver com a natureza, construir frondoso. O outro remete à Arquitetura Sustentável e considera: baixo impacto ambiental, redução da produção e consumo energia, materiais e sistemas construtivos regionais, captação de águas pluviais e reuso de águas servidas.

O projeto da Vila Pajuçara e suas casas de duas frentes priorizou: i) a sustentabilidade social, tendo em conta tratar-se de áreas de risco e de conflitos urbanos, o envolvimento da população loca e a urgência por soluções de rápida execução; ii) a sustentabilidade econômica, considerando as possibilidades vigentes de financiamento público (como o PMCMV) e autossuficiência parcial; iii) a racionalidade construtiva, observando os materiais e sistemas construtivos locais e pré-fabricados; e, por fim, iv) as tecnologias e linguagens contemporâneas de concepção e forma construtiva, incorporando métodos digitais de auxílio ao projeto colaborativo como a plataforma BIM e a parametrização.

Os resultados alcançados cumprem os objetivos propostos. O exercício de concepção e desenvolvimento de um projeto pautado na cooperação entre seis profissionais com diferentes competências, sendo um consultor, e uma estudante/estagiária, em um contexto de concurso, revelou-se de grande relevância para a prática reflexiva e promoção da qualidade arquitetônica. Constituiu, para além disso, uma oportunidade de vislumbrar possibilidades de soluções espaciais para os problemas reais das nossas cidades. Apesar de não se ter compromissos firmados para a execução do projeto, a iniciativa provoca a sociedade a debater alternativas mais humanas e justas no sentido de minimizar os impactos das desapropriações mencionadas na região de intervenção.

\section{REFERÊNCIAS}

BOUDON, P. et al. Enseigner la Conception Architecturale: Cours D’Architecturologie. Éditions de la Villette, Paris. 2000.

BOUTINET, J. -P. Antropologia do Projeto. Tradução: Patrícia Chitonni Ramos. 5a ed. Porto Alegre: Artmed, 2002.

CAIXA ECONÔMICA FEDERAL. Minha Casa Minha Vida. Disponível em: http://www.caixa.gov.br/poderpublico/programas-uniao/habitacao/minha-casa-minha-vida/paginas/default.aspx. Acesso em 25.jun.2018.

CONSELHO DE ARQUITETURA E URBANISMO DE PERNAMBUCO (CAU-PE). Edital nº 01/2018. Prêmio Armando de Holanda Cavalcanti de Arquitetura. Disponível em: <http://www.caupe.gov.br/wp-content/uploads/2018/10/EDITALPremioarmandodeholanda.pdf>. Acesso em 10 de outubro de 2018.

HOLANDA, Armando de. Roteiro para construir no Nordeste - Arquitetura como lugar ameno nos trópicos ensolarados. Recife: MDU/UFPE, 1976.

LAWSON, B. Como arquitetos e designers pensam. São Paulo: Oficina de Textos, 2011.

MEDEIROS, C. B. N. Entre o rural e o urbano: relações socioambientais da AEIS do Gramorezinho e implicações na sua regulamentação. 2017. 297f. Dissertação (Mestrado em Arquitetura e Urbanismo) - Centro de Tecnologia, Universidade Federal do Rio Grande do Norte, Natal, 2017. 
PREFEITURA MUNICIPAL DO NATAL (PMN) / SECRETARIA MUNICIPAL DE MEIO AMBIENTE E URBANISMO (SEMURB). Carlos Eduardo Pereira da Hora. (Org.). Conheça melhor o seu bairro. 2012. Disponivel em: <http://www.natal.rn.gov.br/semurb/paginas/ctd-1166.html>. Acesso em: 25.jun.2018.

PREFEITURA MUNICIPAL DO NATAL (PMN). Lei Complementar $\mathbf{n}^{\circ} \mathbf{0 5 5}$, de 27 de janeiro de 2004. Dispõe sobre o Código de Obras e Edificações do Município de Natal e dá outras providências. Disponível em:

https://www.natal.rn.gov.br/bvn/publicacoes/lei_complementar_n_055.pdf. Acesso em 15 de outubro de 2018.

PREFEITURA MUNICIPAL DO NATAL (PMN). Lei Complementar nº 082, de 21 de junho de 2007. Dispõe sobre o Plano Diretor de Natal e dá outras providências. Disponível em:

http://www.natal.rn.gov.br/semurb/paginas/File/.../24_Plano_Diretor.pdf. Acesso em 15 de outubro de 2018.

\section{NOTAS}

${ }^{1}$ A equipe técnica, cujo projeto recebeu Menção Honrosa na categoria profissional do Prêmio Armando de Holanda Cavalcanti Arquitetura 2018 - CAU/PE, foi constituída pelos profissionais: Maísa Veloso, Heitor Andrade, Luciana de Medeiros, Verner Monteiro e Alessio Dionisi; pela estudante de arquitetura: Mara Raquel; e pela consultora: Gleice Elali.

2 O BIM é compreendido como uma ferramenta que permite criar simulações digitais, manejando coordenadamente todas as informações processadas em um projeto de arquitetura.

NOTA DO EDITOR (*) O conteúdo do artigo e as imagens nele publicadas são de responsabilidade do(s) autor(es). 